\title{
Gateways to accessing powerful RE knowledge: a critical constructive analysis
}

\section{Olof Franck ${ }^{1}$ (i)}

Accepted: 13 January 2021 / Published online: 8 February 2021

(c) The Author(s) 2021

\begin{abstract}
This article examines the conditions for designing an epistemologically grounded teaching about religions through an identification of what knowledge is central to the subject of Religious Education (RE). A starting point for the analysis is a discussion of Michael Young's well-known concept of powerful knowledge, as a possible platform for developing an approach for how a knowledge base in the subject could be identified. The concept of powerful knowledge is shown to be relevant for how epistemological perspectives can be considered in relation to an analysis of the subject's knowledge base. Such an analysis is carried out, and the concept of threshold concepts is introduced to develop a broader and sharper theoretical framework, at the same time as Young's approach becomes the subject of a more in-depth discussion. The presentation leads to a discussion of various considerations relevant to an analysis of how a powerful RE knowledge may be understood.
\end{abstract}

Keywords Religious education · Powerful knowledge $\cdot$ Religious literacy $\cdot$ Threshold concepts

\section{Introduction}

One of the challenges of our time for an epistemologically grounded teaching about religions is to identify what knowledge is central to the subject. Too often, the domain seems to be reserved for answers to the question of why children and young people should learn about religious teachings and traditions, to include more or less instrumental purposes. Religious education (RE), simply put, is assigned the role of a servant of the democratic, multicultural society, where its main contribution is to open doors for a nurturing, and a cultivation, of a respect for and understanding of diversity (cf Barnes 2019.).

There is no reason to despise or generally reject such a purpose. If we seriously mean that the teaching of religions has a place and a role to play in today's society, it is as difficult as it is unjustified to ignore the fact that knowledge of religions may open up for

Olof Franck

olof.franck@gu.se

1 Department of Pedagogical, Curricular and Professional Studies, University of Gothenburg, Gothenburg, Sweden 
discussions on democracy and pluralism, as well as for an interest in existential dimensions of people's lives, and their thoughts about life.

Of course, it is not possible to interpret such an interest in causal terms: a study of religions does not automatically, or on its own, lead to a growing understanding of and respect for people's different views on life. Such an instrumental process also does not seem desirable if it lacks room for critical reflection.

Studying religious beliefs and rites in school while continuously leaving room for students' curiosity, for critical questions concerning doubt and faith, is important to be able to approach the theoretical and practical expressions of religion that one encounters in society. Developing a knowledge of at least the basic features of the diversity of religions and worldviews, and a respect for people's right to relate to them independently, can and should be combined with a critical approach.

Expressed in well-known terminology, it is important that young people be given the conditions to "learn about" religion (Grimmitt 1987). Such knowledge is one part of such a basic societal education that all students are entitled to. I would also like to say, while noting that a closer interpretation of Grimmitt's influential distinction presents challenges (cf. Teece 2010), that they also have a right to "learn from" religions-in the sense of being given relevant conditions for such learning. A teaching of religions cannot, without challenging the demand for the preservation of students' integrity, involve a requirement to experience something of value or meaning in the particular religions being studied, just as such a requirement cannot be linked to a teaching of other views on life, or of philosophical or political ideologies.

Students should, however, be offered the conditions to be able to see religions as historical and contemporary expressions of people's reflections on, and approaches to, issues regarding life's origin and meaning, on their own and in relation to others. Maybe they experience that something is important to consider in relation to their own personal questions. Maybe something seems interesting, or raises discouragementexperiences that may help them make decisions about what they want to think, believe and do, who they want to be (and not be). And not least: maybe there is something to learn in the role of being an active member of various social communities.

Such empathy has a value, no matter where it occurs. In Gert Biesta's terminology we may state that The beautiful risk of education means that the teaching students encounter in a classroom lacks predestined results (Biesta 2013). Children and young people need to be able to learn about knowledge, abilities, norms, and values, and become aware of the traditions within which these things are formulated and practiced. But they also have the responsibility and opportunity to develop their own approach to all this. We will return to Biesta's conception of subjectification (ibid.) later.

\section{Disposition}

In this article, I will discuss the conditions for developing an epistemological foundation for RE through an identification of a subject content in terms of powerful knowledge. The label was first used in a printed publication by Wheelahan (2007), but has since been associated primarily with Michael Young's authorship, in some important articles in collaboration with Johan Muller. 
In my discussion, I will elaborate on Young's approach by exploring how the concept of threshold concepts can prove fruitful in order to develop possible strategies for identifying the concept of powerful RE knowledge.

\section{A socio-epistemic platform for the building of powerful RE knowledge}

A basic idea in Young's thought on knowledge and power is that "A social theory must recognize that some knowledge is objective in ways that transcend the historical conditions of its production, e.g. Euclid's geometry and Newton's physics" (Young 2008, p. 28). A key point in Young's social realistic approach is that knowledge is indeed rooted in the social contexts in which people live and relate to each other and to the world, but that it transcends these contexts.

In an educational arena, according to Young, this means that curricula cannot rest solely on "everyday practical experience" but must also be based on "specialist research and pedagogical communities" (ibid., 89). Knowledge is perceived as "external to learners, it recognizes that this externality is not given, but has a social and historical basis" (Young 2010, p. 22).

Here it is, with Young's thinking in mind, reasonable to highlight that the knowledge to which the school should open a path cannot be limited to lists of facts; lists that are treated as if they were static compositions of essential knowledge summarizing everything that is worth knowing on certain subjects. Such lists not only express a rationalizing view of knowledge, but also alienate the very concept of knowledge from social and historical contexts within the framework of which what should be counted as knowledge develops (cf. Muller and Young 2019).

More precisely, Young and Muller, in a previously published article, considering various paths for how conceptions of teaching and knowledge may develop, describe a scenario reflecting this as a Future 1, a state where strict boundaries make up more or less static structures for social differentiation of both institutions and knowledge. It is, according to Young and Muller, a state "associated with a naturalised or 'under-socialised' concept of knowledge" (Young and Muller 2010, p. 16).

In contrast, Future 2 refers to a state that refers to "The end of boundaries" and an "oversocialised' concept of knowledge" (ibid., 16).

Future 2 is 'born in 'progressive' opposition to Future 1. It envisages a steady weakening of boundaries, a de-differentiation of knowledge and institutions, a blurring of labour market sectors, and a greater emphasis on generic outcomes rather than inputs as instruments of equalisation and accountability" (ibid., 18).

The authors mention several expressions for such a de-differentiation and boundary weekening, for example "the 'integration' of school subjects", "the stipulation of curricular content in generic, usually skill or outcome terms", and "the promotion of formative over summative assessment" (ibid., 18, italics original).

Commenting on this scenario, Young and Muller state that:

Our position...is that educational boundaries are social but also real, not arbitrary, that is, they cannot be dissolved, at least in the short term, without serious consequences for most if not all learners. What such de-differentiating mechanisms are most likely to achieve is not to dissolve the boundaries, but to render them invisible - an invisibility that is exaggerated for the more disadvantaged (ibid., 18-19). 
Young and Muller claim that there is a third scenario, Future 3, in which what I here will call a "socio-epistemic platform" for the building of powerful knowledge, can be identified. The authors claim that this scenario "emphasises the continuing role of boundaries, not as given entities, whether in the brain (neuro-science), in the mind (a-historical rationalism) or in the world of human practice (pragmatism and dialectical materialism), but in defining domain-specific but increasingly global specialist communities as a basis both for the acquisition and production of new knowledge and human progress more generally" (ibid., 20).

\section{Facts, methods and subject-specific infrastructures}

Now Muller and Young (2019) claim that various kinds of theoretical concepts can play a role in powerful knowledge processes in different subjects. Support is expressed for the fact that concepts, by fulfilling cross-disciplinary roles in some respects, can contribute to the development of an overall curricular knowledge whereby different subjects appear with their respective identities, but at the same time are not definitively separated from each other. This is not a relationship that threatens the existence of a subject-specific "powerful knowledge".

Such knowledge is developed on a foundation of substantial knowledge, whereby both relevant sets of facts and subject-related methods and models interact. Here, Muller \& Young speak with reference to Peter Winch about a know how, a knowledge that seems to be perceived as referring to socio-epistemic strategies in accordance with which agents, within the framework of a given subject's arena, approach issues regarding the identification and interpretation of facts, and presumably useful methods with regard to which a pursuit of truth-driven knowledge processes, with relevance to what is perceived as the core of the subject.

Muller and Young argue that the way in which concepts play an active role in subjectspecific knowledge processes may differ. They mention that the subject of physics can be perceived as resting on vertical principles of progression that follow a clear logic for which concepts are to be used and in what way. Such knowledge processes differ from those that characterize the subject of history, where there is no clear "conceptual ladder" and where progression in a curricular context should be interpreted in different ways: "the curriculum of Physics is best ordered by within-topic progression and cumulation. This is not the case in History, which does not progress in the same way, though this does not mean that students cannot progress in their knowledge of history... History's principle of progression is a narrative one, or rather, lies in the progressive deepening of ramifications of the entailment of causal argument" (Muller and Young 2019, p. 207).

A pursuit of truth is exercised in both physics and history, but the requirements for what can be perceived as a successful argument look different. Causal reasoning that follows an "if... then" model cannot be applied identically to the two arenas. In history education, teachers have to watch over how demands for reasonable arguments and conclusions can be built on the platforms that are perceived to constitute substantial knowledge in history. This base can be perceived as more elusive and difficult to interpret than the corresponding base in physics (ibid., 207).

What may this mean with regard to concepts which can be identified as contributing to the impartment powerful RE knowledge? It seems close at hand to compare RE with Muller and Young's example of history education. They are both social science subjects, 
in which theoretical models and concepts seem to follow a different logic than in natural science subjects. This means, among other things, that concepts that are central to each subject can be perceived to function in different ways, in relation to the knowledge bases that can be linked to them. The question of what can be true, and what grounds on which this can be answered, looks different between, and not seldom also within, subjects. This means that the concept of truth, which may be perceived to be central in the development of a powerful RE knowledge, needs to be made the object of an analysis and a discussion of how it should be understood in this context.

Such an analysis seems necessary if one is to avoid allowing these concepts to play a more or less mysterious role in the development of powerful RE knowledge. They are said to be inevitable instruments for developing such knowledge, at the same time as they are recognized as residing in other subject-specific arenas where, it may be assumed, other forms of powerful knowledge are intended to be developed. The relationship between these roles needs to be clarified.

\section{Powerful RE knowledge and religious literacy}

In this context, there is reason to recall the discussions that have long taken place regarding how the concept of religious literacy should be understood. An interesting feature of the debate in recent decades is Stephen Prothero's Religious Literacy. What Every American Needs to Know — and Doesn't, published in 2008. As emphasized in von Brömssen (2013), this publication should be seen as a contribution to the question of whether religious education in a Christian, American context should be offered; a question that Prothero, due to the ignorance he identifies among American youths in matters of even basic knowledge of Christian faith and tradition, answers in the affirmative.

Prothero moves with varying interpretations of the concept of literacy, but in a basic definition he says that religious literacy refers to the ability to understand and use a language - to read and perhaps to write it, to manipulate its vocabulary, grammar and syntax. In this sense religious literacy refers to the ability to understand and use in one's day-to-day life the basic building blocks of religious traditions - their key terms, symbols, doctrines, practices, sayings, characters, metaphors, and narratives (Prothero 2008, p. 14f).

Early on, Prothero's definition, on more or less good grounds, became the object of criticism. As von Brömssen (2013) points out, an important objection was that the definition has a one-sided focus on facts, on a knowledge that stops at superficially approaching religions and religious beliefs.

Perhaps there is a parallel here to Muller and Young's warnings to let topics be defined in terms of relatively delimited lists of facts and concepts that are considered to be the very foundation of what constitutes a subject's knowledge content. I do not find such an interpretation of Prothero unreservedly convincing. After all, he talks about an ability to "understand and use" the "basic building blocks" he identifies. Be that as it may, when one of Prothero's critics, as an alternative approach, emphasizes that "[being] literate about religion" should rather be understood as "[needing] to know something about religious dynamics, mechanics, and processes-the how of religion" (Gallagher 2009, p. 208), then perhaps a broader - and deeper-interpretation of how religious literacy can and should be understood.

The concepts that can contribute to a knowledge base in RE can be described as "theoretical" in the sense that they have an anchor in this field, and can thereby contribute to 
shaping and developing an epistemological basis for powerful RE knowledge. Such knowledge goes beyond learning simple facts about religious beliefs and how these beliefs are expressed in people's lives. Powerful RE knowledge refers to knowledge that is expressed in a deeper recognition of the theoretical and practical forms of religions.

\section{Threshold concepts}

In accordance with the reasoning above, the didactical structure of RE has to be developed with regard to a philosophical and theological foundation. The question of how RE is to be taught cannot be treated in a satisfying way without a focus on how its content is defined, and on what epistemological grounds this content can be justified.

Robert Keuh has suggested that the concepts of truth, identity, culture, and diversity, can be related to the process of developing powerful RE (Kueh 2019). These concepts are, however, quite general, and they can all be linked to different topics and different discourses. It is not obvious what role they can or should be expected to play in the development of powerful RE knowledge. In which way are the concepts thought to contribute to such a development? Do they act as some kind of roadblock for how religious beliefs and religious life should be understood? If so, why is it precisely these concepts that are intended to make such an understanding possible? What is their role, between a substantial knowledge consisting of "basic blocks" of factual and conceptual knowledge on the one hand and a subject-specific knowledge on the other, where such a knowledge base has developed into a powerful RE knowledge rooted in "the field of philosophical and theological discourse"?

It may in this context be worth recalling the analyses carried out with regard to an RE arena based on so-called threshold concepts, developed by Meyer and Land. Threshold concepts refer to steps in the process through which students develop knowledge in a specific area. There are a number of suggestions in the literature on which these concepts are found in an RE arena, and Niemi (2018) points out that there are examples of how such suggestions are linked to a denominational arena.

As I have emphasized, the arena we are dealing with in this article is another one: a nondenominational arena where teaching about religions can aim at a "learning about" as well as a "learning from", but not with the intention of convincing students to take a personal stand for, or against, one or another religious view of life. The purpose is rather to create conditions for developing a relevant and valid knowledge of religions and religious beliefs in theory and practice.

Meyer and Land (2005) mention three properties of threshold concepts: they are transformative, irreversible, and integrative. Being transformative means that they contribute to the person studying a certain subject, being able to look at its form and content in a new light, acquiring a changed perspective, and seeing that previous ideas may be incorrect or at least not reasonable. Perhaps we can express this by saying that the student sees the "substantial knowledge" of the subject in a new light. The concepts being irreversible means that those who have acquired a transformed view of the subject will have difficulty going back to previous, more or less uninitiated, notions. Threshold concepts being integrative means that they create conditions for connecting into a whole the parts that previously appeared to be incoherent. In other words: threshold concepts open up for the development of new insights and new knowledge. Meyer and Land use the term "conceptual gateways" 
to clarify the role threshold concepts play, often in liminal arenas where students are seeking paths to knowledge (ibid., 373).

\section{Threshold concepts in relation to RE knowledge and to Religious Studies}

The analysis carried out by Niemi (2018) states that threshold concepts open up for knowledge in a scientific, academic arena of Religious Studies (RS), and that such knowledge should be able to have relevance and significance for how RE develops in school (ibid., 5). This is an interesting interpretation of the pedagogical role threshold concepts are thought to be able to play. They open up for a scientific, academically grounded knowledge which, via teachers in the subject, takes a place in their teaching, contributing to how RE is designed in the school's arenas. Niemi describes threshold concepts as "didactical tools" that can be central to teachers in their teaching of RE, as they can contribute to thoughtful and progressive approaches to difficulties and challenges in the teaching and learning processes, and to chart paths suitable for collaboratively, together with students, paying attention to and analyzing the subject content that is not always immediately available and comprehensible (ibid., 5).

This interpretation seems possible to link to how Muller and Young reason in the previously quoted article about powerful knowledge as a knowledge base rooted partly in substantial knowledge relevant to the subject, but also in the discipline where the subject has its academic roots. Threshold concepts can be distinguished from core concepts, which are necessary to assimilate for those who want to master an area of knowledge but which the knowledge-seeker has already acquired. This knowledge is "substantial" in the sense of being basic and important for those who want to learn a subject. Threshold concepts, on the other hand, are those through which the novice can see something new, gain insight into previously unknown traces and dimensions of knowledge, and acquire, as Meyer and Land call it, the opportunity to approach a "discursive space" (ibid., 375), where in-depth and broadened recognition of a knowledge area is made possible.

These concepts do not have a given, let alone essential, content. They need to be contextualized in relation to a knowledge content, and to be reconsidered through the knowledge processes in which they play the role of "gateways" (cf. Niemi 2018, p. 5). In this sense, they may look similar to Kueh's above-mentioned candidates for theoretical concepts, through which the development of powerful RE knowledge is claimed to be possible. The proposed concepts of truth, identity, culture, and diversity, which can obviously be applied in different subject contexts, all seem in principle to be able to play a role in a process whereby transformability, irreversibility, and integration in the given sense are made possible. Approaching an RE knowledge base founded on questions of how truth and truth claims are negotiated in religious arenas, how people shape and define their own and others' identity and culture in these arenas, and how diversity characterizes religious as well as secular views on life and what it means for individuals and for groups and communities seems to be valuable and important.

However, a critical question can be directed here at these conceptual candidates, as they seem all too well generalized in order to be fully active in a process that leads to new insights and an expanded and in-depth knowledge of the RE arena. Of course, all four can help in taking a first step toward such a process. But one could object that a greater concretion would be needed for "threshold concepts", to play an optimal role in the development of a powerful RE 
knowledge whereby students are given the conditions for new insights and new knowledge, as well as a developed ability to actively approach, interpret, and cultivate the knowledge content that is presented as central to RE and to critically and constructively analyze the basis for such a presentation. The four conceptual candidates may perhaps look similar to "threshold concepts", but their role is rather to build a general conceptual platform, while "threshold concepts" are thought to work as "gateways" for an entrance to arenas offering conditions for a development of subject centered knowledge.

Niemi selects conceptual candidates in terms of three pairs of concepts with respect to which an RE knowledge base can be approached in hopefully fruitful ways. Common to these concepts is, while they are not entirely easy for a novice in an RE or RS arena to understand, at the same time, through reflection and analysis, they can open up for an ever deeper and broader recognition. A concept that is proposed is the world religion paradigm, i.e. the axiom that underlies much of RE whereby a selection of religions are perceived as ordered complexes of theoretical ideas which are defined in terms of particularly the religions Hinduism, Buddhism, Judaism, Christianity, and Islam. An opposed concept is lived religion, whereby people's concrete, lived expressions of faith are at the center and open up for a problematization of what religion is and can be, and how religion can and should be understood and interpreted. More or less rigid theory is set, in simple terms, against complex, dynamic practice (ibid.,17).

Another pair of concepts consists of orthodoxy-orthopraxia, in which the former is directed at religious contexts in which the "right faith" is at the center while the latter concentrates on questions concerning what constitutes the "right action" (ibid., 16). Niemi mentions Protestantism and Lutheranism as arenas in which orthodoxy plays a prominent role (ibid., 14).

A third concept pair has emic-epic as its poles, i.e. as points of reference for how religious traditions can be described from either an inside perspective (emic) or an outside perspective (epic). Seeing and understanding what it means from which points of departure, and from which context religion and religious belief are presented, provides opportunities to approach such descriptions from a critical, constructive perspective.

There is reason to discuss Niemi's proposals as perhaps pedagogically more concrete and clearer than Kueh's four candidates, but it is not certain that one needs to choose here. Threshold concepts are not logically, or in an essential sense, exclusively anchored only in a specific discipline or a specific subject, and several types of such concepts can prove useful as "gateways" for RE and RS students. In an RE or RS arena, it is conceivable that each of them can play a role as transformative, irreversible, and integrative in the knowledge processes by which powerful RE knowledge is cultivated, nurtured, and developed, even if this can be done in different ways.

Here, there is a possibility of pluralism within the framework of both the academic discipline RS and the subject RE, where different parts of a collected subject-specific knowledge exist side by side. There could be pedagogical tools that would be of help within an RE context, with its specific codes for analysis and argumentation, although mostly in an assistant role. An analytical treatment of so-called religious experiences, for example, could be of great benefit through the use of not only theologically anchored threshold concepts but also others with a foundation in psychology and science, as well as philosophy.

Here, perhaps one could imagine levels of generality and specialization, whereby certain threshold concepts can play a pedagogical role in relation to different subject-based and disciplinary arenas, while others' roles are more specific to a certain subject and a certain discipline? However, this is a question that may need to be left for another context. 


\section{Know how, threshold concepts and powerful RE knowledge}

Even with Niemi's proposal, however, there is a lack of a concrete definition concerning which RE knowledge is to be regarded as powerful. As "gateways", the threshold concepts contribute to opening up toward understanding substantial RE knowledge with regard to the interpretive norms and conceptual understandings that exist in not least a theologicalbut also, among other things, a philosophical—arena. It is not a question of reaching definitive conclusions as to what such a consideration leads to: conformity with or deviation from perceptions, more or less traditional, which are waiting to be discovered and acquired. It is not a matter of discovering a treasure that must be passively made into the applicant's or novice's own. Rather, it is a question of how knowledge of the ways in which this treasure, perceived as a knowledge base, should be investigated, interpreted, developed, passed on.

If powerful RE knowledge refers to a cemented content that is unchanging, it will rather be a matter of dogmatism-which seems far from Young's understanding. And this means that the purpose of the knowledge process with threshold concepts is not that novices, students, should reach a predetermined goal, but that they should develop a knowledge, a know how, in order to be able to participate in a progressive way in a continuous movement that offers new ways of looking at and relating to how religion and religious belief are expressed in theory and practice.

Perhaps it is again appropriate to recall the expression the beautiful risk of education: students - to speak with reference to Biesta's well-known conceptions of functions of education-are entitled to socialization, a learning about the knowledge bases in different subject arenas as well as about the norms, values, and traditions that constitute the socioepistemic context to which the student belongs, as well as to qualification as a citizen, the capability to act as a competent citizen (Biesta 2013, p. 64). These functions make up a platform in relation to which a student has to develop an approach, anchored in critical as well as constructive interpretation, being the object for argumentative decisions. This is an arena for subjectification, a process whereby the student breaks free and develops independence as an autonomous subject (ibid, 64).

Emancipatory education does not start from scratch but rather develops from a given socio-epistemic context. The question of how this context is defined, maintained, and developed raises issues regarding power. Such issues may be raised on general societal levels, as well as with regard to specific disciplines and subjects.

When it comes to RE knowledge, we need to remind ourselves that, just as in other social science and humanities subjects, there is little room for necessary truths. As Muller and Young state, we are, in these arenas, dealing with subjects-and academic disciplines-where possibly relevant and fruitful "conceptual ladders" need to be continuously analyzed and tested. Argumentation in these arenas differs from, for example, that in physics or mathematics: it is horizontal rather than vertical; i.e., it does not necessarily follow existing logical structures in which the relationship between subject-related concepts has a mutual order. This is not a problem for the credibility of the social sciences or humanities. It is a sign that the know how that characterizes and develops the subjects here has a different basis and structure than that in, for example, physics or mathematics.

If, with Niemi (ibid., 5), we believe that the choice of threshold concepts in, for example, an RE and RS arena can give slightly different results depending on what kind of area is being studied, and that this choice is influenced by the nature of the subject studied and the tentative content and vice versa, it becomes a situation in which the choice of 
"gateways", threshold concepts, needs to be negotiated in relation to how the content and knowledge contribution of the subject and discipline are perceived. This raises the question of who should have the power to lead such a negotiation. Is it theologians? Or philosophers? Is it RS researchers in other fields? Is it the teachers who train RE teacher students? Is it the teachers teaching RE at the school? Is it the authors of the curricula that regulate teachers' teaching in the subject?

If, as I have argued, it is important to try to identify a knowledge base for RE, a powerful RE knowledge, and if such an identification does not have a given, even less necessary, form, then the question of power with regard to such a socio-epistemic process must be addressed. And here it is fruitful to, once again, turn to Muller and Young's previously quoted article in which the issue of powerful knowledge is discussed in relation to both an academic arena and school subjects and curricula.

\section{Knowledge of the powerful (KOTP) in the RE and RS arenas}

How can the conception of powerful RE knowledge be described in a more specific way? I believe that in order to interpret this concept, we first need to recall the distinction between "powerful knowledge" (PK) and "knowledge of the powerful" (KOTP) that Young, together with Muller, has analyzed quite extensively.

While PK refers to a core body of subject-specific knowledge to make available to students, KOTP has its reference area in "its use and origins, and the interests of those users and originators" (Muller and Young 2019, p. 197). Those who have the power to, for example when designing curricula, interpret and organize knowledge, can choose progressive as well as regressive strategies, depending on which interests are in focus. PK and KOTP do not refer to two types of knowledge; only PK has such a reference. As Muller and Young put it: "Social interests do not exhaust what is educationally significant about knowledge" (ibid, 197).

This means that "power" means different things in the two cases. According to Muller \& Young, KOTP is not "transferable from the power holder to those subjected the power, unless the subjected actors manage to negotiate its transfer or wrest it back by force. In other words, this sense of power is a finite or zero-sum property-what the one has, the other cannot have... In PK, by contrast, the power is potentially available to all who acquire it; it is a non-zero-sum property, a non-rivalrous good. Potentially, everyone can have this power, it is infinitely transferable, hence the fundamental democracy of PK and its conceptual link to social justice" (ibid., 197f).

This is an important difference to consider for anyone who, based on Young's-and Muller's-approach, wants to take an epistemic-democratic perspective on what subjectspecific powerful knowledge can contribute in curricular arenas. Who decides what is a subject-specific knowledge contribution; and in what way can and should this be made available? As Muller and Young point out (ibid., 198), KOTP has its domicile in a political arena, while "PK belongs to the socio-epistemic domain, and gestures towards characteristics of knowledge that are objective features of the knowledge in question, and can thus be identified. It also points towards a 'power', or at least a potential power, that can be conferred upon the actor (acquirer or producer) by the PK, as a benefit in itself or as a means to alter the properties and potentials of our environment" (ibid., 198).

The meaning of this description seems to be that the rulers of the political arenas can certainly try to limit or prevent people from acquiring such knowledge, that makes 
it possible to develop a deep recognition of the core content of subject-specific powerful knowledge. But there are, it is said, "characteristics" that constitute "objective features" of knowledge, and here at least a "potential power" is also identified for actors that enables them to be involved, to influence, to take their place in ongoing knowledge processes.

Muller and Young, in their article, make a reference to a know how, a knowledge that seems to encompass a capability to see, understand, and critically approach the substantial knowledge - the facts and the concepts - that is assumed to frame the knowledge base of a certain subject, according to its specific principles for progression (ibid, 205). Muller and Young label such principles "narrative" when it comes to history education (ibid., 206f), and it seems reasonable to assume that RE, perceived as a subject with its roots in both the social sciences and the humanities, could also fall under a such designation.

What can the distinction between PK and KOTP, as perceived here, mean in relation to the concept of powerful RE knowledge, interpreted with reference to the concept of threshold concepts?

The most important lesson here is that the conditions for the development of a powerful RE knowledge cannot be perceived as either determined, or independent, by those with the power over "the use and the origins" of such a knowledge. When it is determined which place and which contribution RE should be attributed to in curricular arenas, there is an arsenal of possible KOTP actors with the opportunity to influence and make decisions. There is always reason to critically discuss such decisions: this is part of a democratic curricular process.

A reasonable interpretation with reference to Muller and Young's argumentation, however, is that curricular decisions are not determined by unrestricted claims on how the subject RE (and other subjects) should be perceived from a subject-specific perspective. Within the framework of the subject's reference area, there are identifiable objective knowledge dimensions, powerful knowledge, which in principle are possible for those who study the subject to-regardless of political power structures-absorb and develop within the framework of a deepening recognition of the subject. As Michael Reiss puts it with reference to Young's work: "This social realist approach allows Young to reject both relativism and postmodernism, and also to avoid a naive version of positivism" (Reiss 2018, p. 3).

\section{Final comments}

We have now reached a point in the analysis where it is reasonable to ask what the previous discussion has led to. In the introduction I described a quite frustrating situation where RE too often seems to be treated in an instrumental way, where the purpose of the subject is formulated in terms of specific goals, potentially satisfying a need for a cultivating respect for democratic values in a multicultural and diversified society. Such goals are important and praiseworthy, but if the focus is exclusively directed towards them, the need for anchoring teaching in the subject in the building of a solid and dynamic base of knowledge will be neglected. Such a neglect will have significant consequences.

The aim with the present analysis is to develop a framing of an approach which could serve the purpose of building a solid and dynamic knowledge base for RE. I have, in this context, turned to the approach presented by Young, in collaboration with Muller, and made the concept of powerful RE knowledge a main object of examination.

This examination has led to an analytical position which can be said to relate to what Young and Muller describe as scenario Future 3, where "the continuing role of boundaries 
are emphasised, not as given entities...but in defining domain-specific but increasingly global specialist communities as a basis both for the acquisition and production of new knowledge and human progress more generally (ibid., 20).

As previously stated, Young believes that there is an objective knowledge, in that it transcends people's everyday experience, and that it is necessary for this knowledge to be assigned a clear and supportive place in the curriculum. The concept of powerful knowledge that Young uses to refer to this knowledge can be interpreted more or less strictly. As Osbeck (2020) remarks, the concept has been perceived as too narrow to be applied in education in a broad sense, as it refers to a knowledge that is produced in academic arenas, and is conceived of as differentiated from students' experiences in a way that makes the boundaries between school and academy, subjects and disciplines, strict and definite (ibid., 6).

In the present context, I have interpreted Young's approach in a less restricted way. Making use of a terminology in Muller and Young $(2019,206)$, the analysis can be said to present what may be called a socio-epistemic "infrastructure", building a platform for the development of powerful knowledge, which seems to include both a substantial base of knowledge and a know how, regarding the interpretation and use of the conceptual resources that are related to this base. The base consists of subject-specific material, for example facts, concepts and theoretical framings. According to the present interpretation, the conceptual resources can be related to the subject-specific base, either as parts of the base or as conceptual tools by which students can be helped to approach and understand the content of the base-and develop a conception of how this content is structured and communicated according to certain "principles for progression".

In the present analysis, I have integrated the concept of threshold concepts, pedagogical "gateways" that offer tools for students to approach and respond to the complexity of the content of the subject. These concepts can be more or less directly subject-specific. Furthermore, in the present context the knowledge base of RE is not perceived as invariant or unchanging. Muller and Young's discussion about the "horizontal" principles of progression seems to make room for a quite dynamic interpretation of the concept of powerful knowledge, in terms of a "narrative" know how.

Applied to RE, it is possible to regard powerful RE knowledge as consisting of a range of facts and concepts connected to different religious traditions, which, in an academic RS arena, are approached from a variety of theoretical and methodological frameworks. This complex material constitutes the (academic) foundation of RE knowledge; that is to say, powerful knowledge that students in school, in accordance with fruitful pedagogical strategies, are entitled to be acquainted with. This process may be conceived of in terms of two of Biesta's conceptions of the functions of education-socialization and qualification-while the third, subjectification, is to take place in relation to this socio-epistemic background.

We must not forget that Young emphasizes that objective knowledge, which transcends everyday experience and rests on "specialist research and pedagogical communities", should be given a prominent role in curricula. That is to say, researchers as well as representatives of pedagogical communities are expected to be involved in what is going on when powerful, subject-specific knowledge is identified, shaped, and made the object of interpretation and analysis. It does not seem unreasonable to expect this process to proceed in two directions: from the academic arena of disciplinary research to the school arena of subject-specific education, and vice-versa. The conceptions of what should count as powerful knowledge in the RS arena, under favorable conditions, will contribute to a corresponding conception in the school arenas whereby teachers will develop pedagogical strategies according to "narrative principles of progression" in order to approach what should 
count as powerful RE knowledge. Correspondingly, these pedagogical strategies may be of interest to those researchers-for example theologians, philosophers, sociologists, and psychologists of religion-who aim to cultivate an ambition to spread an awareness of their research outside the academic context.

\section{Conclusion}

The picture, then, appears to be that the development of powerful RE knowledge can hypothetically be conceived of as democratically structured, with a reasonable division of labor between researchers and teachers. This, however, seems to be at best an ideal. In practice, the "Knowledge of the Powerful", the "KOTP" to use Muller and Young's acronym, with regard to RE as well as other subjects, seems to largely be exercised somewhere else: on the administrative and political authorities in charge of the design of, and the formal decisions regarding, the form and content of curricula.

In his authorship, Young has focused on how powerful knowledge can, and should, be prominent in a curriculum. In the RE arena, this focus raises the question presented at the beginning of this article: what the preconditions are for developing an epistemological anchoring for RE, through an identification of a subject content in terms of powerful knowledge.

Let us remind about Young's basic idea that curricula cannot rest solely on "everyday practical experience" but must also be based on "specialist research and pedagogical communities". Teachers regarded as subject experts, as well as researchers regarded as academic experts, are both needed for the task of curricular leadership. The foregoing analysis offers strong reasons for the involvement of both researchers and teachers in curricular processes, in order to identify what should count as powerful RE knowledge, and to justify its prominence in the RE curriculum.

It seems important to develop different kinds of collaboration where participants are given opportunities to contribute to analyses and discussions regarding various dimensions of what may be conceptualised as powerful RE knowledge. A range of conceptions of how this concept can and ought to be explained with regard to substantive, as well as pedagogical, issues will be expected, and this is a fact that should be welcomed. Questions regarding which core concepts, and which threshold concepts, that may make up a substantive and pedagogical platform for identification, and a development, of powerful RE knowledge, will meet various kinds of responses. An inclusive strategy for examination of, and a dynamic dialogue about, how such a knowledge base can, and ought to, be developed for RE, is fundamental for any analytical approach designed with regard to the aim of balancing between subject-specific and subject-transcending approaches to a constructive and critical understanding of the concept of powerful RE knowledge.

Funding Open Access funding provided by University of Gothenburg.

Open Access This article is licensed under a Creative Commons Attribution 4.0 International License, which permits use, sharing, adaptation, distribution and reproduction in any medium or format, as long as you give appropriate credit to the original author(s) and the source, provide a link to the Creative Commons licence, and indicate if changes were made. The images or other third party material in this article are included in the article's Creative Commons licence, unless indicated otherwise in a credit line to the material. If material is not included in the article's Creative Commons licence and your intended use is not 
permitted by statutory regulation or exceeds the permitted use, you will need to obtain permission directly from the copyright holder. To view a copy of this licence, visit http://creativecommons.org/licenses/by/4.0/.

\section{References}

Barnes, L. P. (2019). Crisis, controversy and the future of religious education. London: Routledge.

Biesta, G. J. J. (2013). The beautiful risk of education. London: Paradigm Publishers.

Counsell, C. (2018). Taking curriculum seriously. IMPACT, Chartered College of Teaching, (4).

Gallagher, E. V. (2009). Teaching for religious literacy. Teaching Theology and Religion, 12(3), $208-221$. https://doi.org/10.1111/j.1467-9647.2009.00523x.

Grimmitt, M. (1987). Religious education and human development. Great Wakering: McCrimmons.

Kueh, R. (2019). Religious knowledge and the 'knowledge problem'. In M. Castelli \& M. Chater (Eds.), We need to talk about religious education. Manifestos for the future of RE (pp. 53-70). London: Jessica Kingsley Publishers.

Meyer, J. H. F., \& Land, R. (2005). Threshold concepts and troublesome knowledge (2): Epistemological considerations and a conceptual framework for teaching and learning. Higher Education, 49, 373-388.

Muller, J., \& Young, M. (2019). Knowledge, power and powerful knowledge revisited. The Curriculum Journal, 30(2), 196-214. https://doi.org/10.1080/09585176.2019.1570292.

Niemi, K. (2018). Religionsvetenskapliga tröskelbegrepp: stötestenar och språngbrädor vid utvecklingen av ett ämnesperspektiv [Threshold concepts in Religious Studies: stumbling blocks and springboards in the development of a subject perspective]. Nordidactica Journal of Humanities and Social Science Education, 2, 1-22.

Osbeck, C. (2020). Powerful knowledge? A multidimensional ethical competence through a multitude of narratives. HTS Theologiese Studies, 76(1), a5830. https://doi.org/10.4102/hts.v76i1.5830.

Prothero, S. (2008). Religious literacy. What every American needs to know-And doesn't. New York: HarperCollins.

Reiss, M. J. (2018). Biology education: The value of taking student concerns seriously. Education Sciences, $8(3), 130$.

Teece, G. (2010). Is it learning about and from religions, religion or religious education? And is it any wonder some teachers don't get it? British Journal of Religious Education, 32(2), 93-103. https://doi. org/10.1080/01416200903537399.

Von Brömssen, K. (2013). Religious literacy—är det ett användbart begrepp inom religionsdidaktiskPedagogisk forskning? [Religious literacy-Is it a useful concept in religious didactic pedagogical research?]. In B. Afset, K. Hatlebrekke, \& H. Valen Kleive (Eds.), Kunnskap til hva? [Knowledge for what?] (pp. 117-144). Trondheim: Akademika Forlag.

Wheelahan, L. (2007). How competency-based training locks the working class out of powerful knowledge. British Journal of Sociology of Education, 28(5), 637-651. https://doi.org/10.1080/014256907015055 40 .

Young, M. F. D. (2008). Bring knowledge back in: From social constructivism to social realism in the sociology of knowledge. London: Routledge.

Young, M. (2010). The future of education in a knowledge society: The radical case for a subject-based curriculum. Journal of the Pacific Circle Consortium for Education, 22, 21-32.

Young, M., \& Muller, J. (2010). Three educational scenarios for the future: Lessons from the sociology of knowledge. European Journal of Education, 45(1), 11-27.

Publisher's Note Springer Nature remains neutral with regard to jurisdictional claims in published maps and institutional affiliations. 